\title{
Erratum to: Assessing response behaviour of debris-flows affected communities in Kaohsiung, Taiwan
}

\author{
Yuner Luo $\cdot$ Rajib Shaw $\cdot$ Hanliang Lin $\cdot$ Jonas Joerin
}

Received: 12 June 2014/ Accepted: 12 June 2014/Published online: 21 June 2014

(C) Springer Science+Business Media Dordrecht 2014

\section{Erratum to: Nat Hazards \\ DOI 10.1007/s11069-014-1258-5}

Due to an oversight, information was missed in the legend of Table 2.

The legend should read:

Table 2: Early-warning and evacuation times in eight villages during Typhoon Morakot (Source: adapted from SWCB)

The full reference also to be added to the article is:

Soil and Water Conservation Bureau (SWCB) (2009) 2009 Taiwan's sediment hazards general report. SWCB. Accessed on 13.8.11. http://webarchive.swcb.gov.tw/web/246. swcb/246old.swcb.gov.tw/ImpNewsShow_noScript.html (in Chinese).

The online version of the original article can be found under doi:10.1007/s11069-014-1258-5.

Y. Luo $(\bowtie) \cdot$ R. Shaw

Graduate School of Global Environmental Studies, Kyoto University, Kyoto, Japan

e-mail: luo.yuner@gmail.com

H. Lin

Department of Urban Planning, National Cheng-Kung University, Tainan, Taiwan

J. Joerin

Department of Environmental Systems Science, ETH Zurich, Zurich, Switzerland 